\title{
Murat Nehri Kıyısında Bir Urartu Yerleşimi: Murat Tepe Kitabı Üzerine Değerlendirmeler
}

\section{Review of An Urartian Settlement on the Bank of the Murat River: Murat Tepe}

\author{
Murat Nehri Kıyısında Bir Urartu Yerleşimi: Murat Tepe (Eds. Abdulkadir Özdemir, \\ Ziya Kılıç). İstanbul: Ege Yayınları, 2021. 196 sayfa. ISBN 9786057673916.
}

\author{
Ali Çifçi ${ }^{1}$ (1)
}

\section{Anahtar kelimeler}

Murat Tepe, Karayolu Ağı, Urartu, Orta Demir Çağı

Keywords

Murat Tepe, Road Network, Urartu, Middle Iron Age

Kalehan Enerji’nin katkıları ile hazırlanan kitap üç sunuş, bir önsöz ve sekiz bölümden oluşur. Bu bölümler bağımsız birer ayrı makale şeklinde yazılmış olup her bir makalede Türkçe ve İngilizce özetlere yer verilmiştir. Kitap Bingöl ilinin Solhan ilçesinde Murat Nehri kıyısında yer alan aynı adlı köyde 2018 yılında Aşağı Kaleköy Barajı su tutma havzası içinde bulunan Murat Tepe'de gerçekleştirilen kurtarma kazısı sonuçlarını 'tanıtmaktadır'. 2018 yılında gerçekleştirilen kazılarda alanının tamamı kazılarak iki yerleşim tabakası ortaya çıkarılmıştır.

Doğu Anadolu Bölgesi’nde Van Gölü Havzası da dahil olmak üzere höyük tarzı yerleşim alanlarında sınırlı sayıda kazı çalışmaları yapılmıştır. Bölgede Orta Demir Çağı (Urartu) arkeolojisi daha çok Urartu krallarının kurduğu merkezlerin kazılması şeklinde gelişmiştir 
(Çifçi, 2017, pp.23-24; Çifçi, 2020, pp.17-18). Bu tarz yerleşim alanlarında daha çok arkeolojik eser (yazıt, metal eserler vb.) ortaya çıkması kazı için tercih edilmelerindeki temel kriteri oluşturur. Bu nedenle Murat Tepe kazısı bölgede Van Gölü Havzası dışında, bu dönemde özellikle merkezi Urartu yönetimi dışındaki yerleşim alanlarının anlaşılması açısında önemli bir konuma sahiptir. Ayrıca kazıda elde edilen sonuçların bu kadar kısa bir sürede yayına hazırlanmış olması bölge arkeoloji açısından önemini daha da arttırmıştır.

Kitabın sunuş ve önsöz kısmında Murat Tepe'nin ismi ile ilgili çelişkili ifadelere yer verilmiştir. Başlangıçta I. derece arkeolojik sit alanı olan Murat Tepe Höyüğü'nün isminin Norik Höyük adı ile tescilli olduğu belirtilmiştir (ss. 7, 9, 13). Ancak ilginç bir şekilde giriş kısmında belirtilen Norik adının daha sonra neden Murat Tepe olarak ifade edildiği konusunda bir açıklamaya yer verilmemiştir. Höyüğün neden bu şekilde isimlendirildiği konusuna sunuş veya önsöz dışında ayrı bir bölümde kısa bir açıklama getirilmesi daha uygun olurdu.

Kitabın ilk bölümünde Murat Tepe'nin kurulu bulunduğu bölgenin jeolojisi, iklimi, bitki örtüsü ve toprak özellikleri hakkında genel bir değerlendirme yapılmıştır. Murat Tepe Höyüğü 'nün yer seçiminde Murat Nehri'nin yatak genişliği ile bölgenin uygun iklimsel koşulları ve görece kurulu bulunduğu alanın çevresine göre alçak ve korunaklı olmasının önemli rol oynadığ 1 anlaşılmaktadır.

Kitabın ikinci bölümü Murat Tepe'deki kazı çalışmalarını ve tabakalanmasını konu edinmesine rağmen kısaca I. tabakaya değinerek Orta Demir Çă̆ı/Urartu Krallığı dönemine tarihlendirilen II. tabakaya dair bir giriş niteliğindedir. Yerleşmede ki I. tabaka belirli bir plan vermeyen, düzensiz ve tahrip olmuş duvar kalıntıları ile temsil edilen Bizans Dönemini oluşturmaktadır. Bu tabakanın en önemli buluntusu Makedonya Hanedanlık dönemine ait olan I. Ioannes Tzimiskes'e ait bir sikke oluşturmaktadır (ss. 44-45).

Kitapta yer alan üçüncü bölüm ise Murat Tepe'de Urartu Dönemi'ne tarihlendirilen II. kültür tabakasını oluşturmaktadır. Urartu Krallığı ile ilişkilendirilen bu tabakada 29 x 19 m. boyutlarında ve beş odadan oluşan bir yapı ortaya çıkarılmıştır (ss. 50-52 Fig. 3-4). Bu yapı Orta Demir Çağı'nda bölge yerleşimleri olan Norşuntepe ve Zülümtepe gibi yerleşim alanlarından bilinmektedir. Murat Tepe'de ortaya çıkarılan bu yapı kalıntısının Urartu Krallığı tarafından bir konaklama merkezi olarak kurulduğu ifade edilmektedir. Urartu Krallı̆̆g’nın merkezi Van Gölü Havzası ile krallığın batı bölgeleri (Elazığ - Alzi) arasında bir karayolunun var olduğu ve Murat Tepe'nin bu karayolu güzergâhı üzerinde bir konaklama merkezi olduğu iddia edilmektedir. Böyle bir öneriyi desteklemek için de yerleşim yerinde yapılan arkeolojik kazılarda ortaya çıkarılan çok odalı ve köşeleri rizalitli dikdörtgen mimari yapı kanıt olarak öne sürülmüştür.

$\mathrm{Bu}$ mimari yapının daha önce bölgede yapılan çalışmalarda konaklama istasyonu olarak tanımlandığı belirtilmektedir (Sevin, 1989). Ancak bölgede bulunduğu iddia edilen karayolunun 
geçtiği alanlarda tespit edilen yerleşmelerde şimdiye kadar herhangi bir arkeolojik kazı yapılmamıştır. Bu nedenle burada tanıtılan yapının Urartu Krallığı tarafından mı yapıldığ veya işlevinin ne olduğu konusundaki yaklaşımlar hipotetiktir. Ayrıca söz konusu yapının bu karayolunu kullanacakların konaklama, yiyecek ve içecek ihtiyaçlarını karşıladığı belirtilmiştir. Ancak boyutları düşünüldüğünde yerleşmenin askeri veya konaklama işlevi taşıdığını açıklamak zor görünmektedir. Murat Tepe'de yapılan kazılarda Urartu Dönemi yerleşimlerinden tipik olarak karşımıza çıkan depo alanları veya hayvan barınağı/ahırı gibi birimlere rastlanmamıştır. Yine çalışmada da belirtildiği gibi kazılarda kılıç, kalkan, miğfer, mızrak veya ok ucu gibi askeri karakterli herhangi bir metal eserin olmadığı anlaşılmaktadır (s. 55).

Kitapta bulunan dördüncü ve beşinci bölümler Murat Tepe'de bulunan Orta Demir Çağı seramiklerinin hem biçim ve form hem de arkeometrik analiz sonuçlarını sunmaktadır. Yine altıncı bölümde Urartu Dönemi'ne tarihlendirilen ve Mezar 2'de ele geçirilen bronz kemer parçası ve yedinci bölümde ise yerleşmenin I. tabakasında bulunan Bizans Dönemi seramiklerinin arkeometrik analiz sonuçları incelenmiştir.

Murat Tepe kazılarında ortaya çıkarılan mimari yapının Elâzığ ile Bingöl illeri arasında Urartu Krallığı tarafından inşa edildiği ifade edilen yol üzerinde bir konaklama istasyonu olduğu fikri yeniden değerlendirilmelidir. Van Gölü Havzası ve çevresinde yapılan ilk çalışmalarda Elâzığ ile Bingöl illeri arasında tespit edilen bu yol gibi bulunan birçok arkeolojik kalıntının kullanış veya yapılış dönemleri tam olarak anlaşılmadan Urartu Krallı̆̆ dönemine tarihlendirilmişlerdir (Çifçi ve Gökce, 2021, pp.229-230). Urartu krallarının çeşitli inşaat projeleriyle krallık topraklarının kalkınmasında ve gelişmesinde aktif olarak yer aldıkları bilinmektedir (Çifçi, 2017). Krali inşa yazıtları su, depolama tesisleri ile kale veya kült karakterli yapıların genellikle Van Gölü Havzası ve Ermenistan'ın Ararat Ovası'nda yapıldığını gösterir. İran'ın Urmiye Gölü Havzası ve Anadolu'nun kuzeydoğusundaki alanlarda olduğu gibi, söz konusu karayolu kalıntısının bulunduğu Bingöl, Muş ve Elazığ ovalarında da bu tür yapılar için çok sınırlı sayıda arkeolojik ve yazılı veri bulunmaktadır. Doğu Anadolu'dan gelen arkeolojik ve yazılı veriler, Urartu Dönemi’nin bölge arkeolojisi/ tarihi içinde önemli olduğunu, ancak tek olmadığını açıkça ortaya koymaktadır. Bu nedenle, gerçek tarihleme verileri (tarihlenebilir arkeolojik kalıntılar veya yazıtlar vb.) olmadan bu tür kalıntıları Urartu Dönemi'ne veya doğrudan merkezi krallık tarafından inşa edildiklerini öne sürmek çok doğru bir yaklaşım değildir. Dolayısıyla bu 'karayolu(?)"nun Pers/Ahamenid, Roma, Bizans ve hatta Osmanlı dönemlerinde yapılmış olma ihtimalini göz önünde bulundurmamız gerekebilir (Çifçi ve Gökce, 2021, pp.230).

Urartu Dönemi’nde Doğu Anadolu' da özellikle dağlık ve merkeze uzak alanlarda bulunan farklı ve yerel kültürler hakkında (Danışmaz, 2020) az bir bilgiye sahibiz ve Murat Tepe'de bu bağlamda değerlendirilmelidir. Birçoğu Van Gölü Havzası'nda bulunan Urartu krali yerleşim alanlarından uzakta dar vadi ağızlarında veya küçük ovalarda olan bu yerleşmeler maddi 
kültür kalıntıları açısında daha çok yerel özellikler göstermektedir. Ancak Murat Tepe'de ele geçen metal eserler bu tarz yerleşimlerin Urartu yerleşim yerleri ile etkileşim içerisinde olduklarını ve çok da izole olmadıklarını göstermektedir.

Murat Tepe Höyügü kazısı, Bingöl gibi çok az araştırmaya sahne olmuş bir bölgede yapılmış olması ve ortaya çıkarılan mimari kalıntılar ile küçük buluntular Orta Demir Çağı'nda Urartu krallık merkezleri dışında kalan bölgelerde bulunan yerel kültürler hakkında bize önemli bilgiler sunmaktadır. Kitap içerisinde yer alan bölümler çok sayıda harita, tablo, çizim ve fotoğraflar gibi görseller ile desteklenmiştir. Kazı sonuçlarının kısa süre içerisinde gecikmeden bilim dünyasına sunulması bölge arkeolojisinin gelişmesine önemli katkılar sağlayacaktır.

\section{Kaynakça/References}

Çifçi, A. 2020. "Urartian Studies During the Foundation of Modern Nation States: Archaeological Traditions, Ideologies and Perceptions" Ancient West and East 19: 1-42.

Çifçi, A. 2017. The Socio-Economic Organisation of the Urartian Kingdom. (Culture and History of the Ancient Near East Vol. 89) Leiden: Brill.

Çifçi, A., Gökce, B. 2021. "II Have Made a Highway of Biainili': Transportation and Road Networks in the

Territories of the Urartian Kingdom”Altorientalische Forschungen 48/2: 221-232.

Danışmaz, H. 2020. Urartu Krallı̆̆ı Yönetim ve Organizasyon. Ankara: Türk Tarih Kurumu Yayınları.

Sevin, V. 1989. "Urartular'a ait Dünyanın en Eski Karayolu” Anadolu Araştırmaları 11: 47-63. 